\title{
„Radiologie von der Locke bis zur Socke“
}

\author{
Abschiedssymposium für Prof. Dr. Lothar Heuser am \\ 29. September 2012 in Bochum-Langendreer
}

Bewusst nicht als Rückblick gestaltet, sondern als in die Zukunft weisendes Symposium fand am 29. September im Knappschaftskrankenhaus Bochum-Langendreer der Abschied von Prof. Dr. Lothar Heuser statt. „Aktuelle Entwicklung in der Interventionellen Radiologie“ war ein von Prof. Heusers langjährigem Oberarzt PD Dr. Matthias König (Lünen) organisierte Veranstaltung, die sich der gesamten Bandbreite interventioneller Radiologie widmete: von der Myomembolisation (G. Richter) über die ,interventionelle Hexenküche" beim hepatozellullärem Karzinom (T. Helmberger), Interventionen beim Polytrauma (V. Nicolas) und den verschiedensten interventionellen Anwendungen bei Gefäßschädigungen(W. Gross-Fengels, I. Wanke, M. König, G. Schulte-Altedorneburg). Viele der auf dem Symposium präsentierten Methoden sind in Zusammenarbeit mit dem umtriebigen Netzwerker und unkonventionellen Lehrmeister Lothar Heuser entwickelt worden, wie alle Referenten gleichermaßen betonten. Dies gilt auch für die Gründung der Deutschen Gesellschaft für Interventionelle Radiologie (DeGIR) und die flächendeckende Einführung der DeGIR-Qualitätssoftware (BQS) für interventionelle Fälle - 2 berufsund wissenschaftspolitische Meilensteine Lothar Heusers, die Bernhard Lewerich, ehemaliger Geschäftsführer der DRG, in seinem Vortrag herausarbeitete.

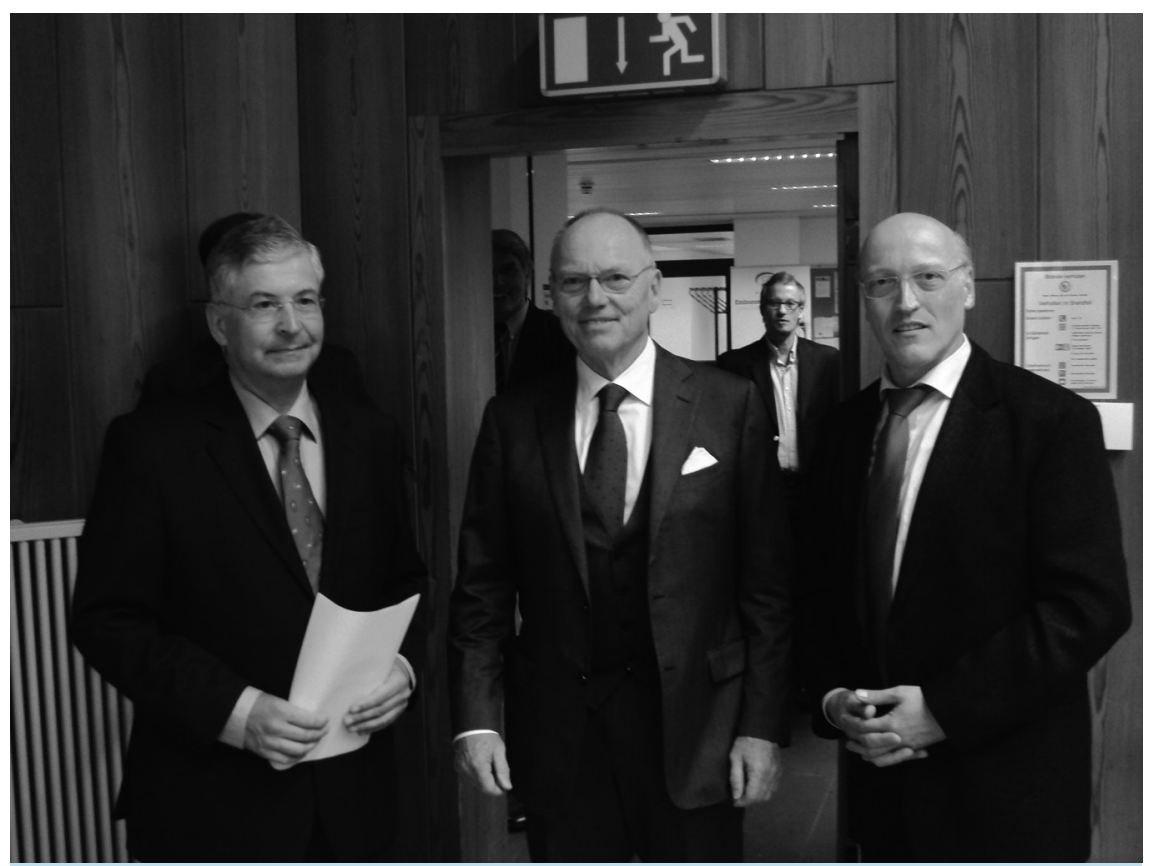

Prof. Richard Viebahn, Chirurgische Klinik Bochum-Langendreer (links), und PD Dr. Matthias König, Marienkrankenhaus Lünen, umrahmen Prof. Dr. Lothar Heuser. 